\title{
Platelet-Rich Plasma in the Management of Chronic Endometritis Treatment in Women with Reproductive Health Disorders
}

\author{
V. O. Sklyarova, K. L. Shatylovich, A. L. Filipyuk, P. O. Sklyarov, and R. A. Chajkivskyj
}

\section{ABSTRACT}

Background: Chronic endometritis (CE) is one of aggressive factor of infertility and reproductive losses.

Objective: We aimed to assess the effectiveness of using platelet-rich plasma (PRP) treatment of chronic endometritis (CE) treatment in women with infertility (PI) and recurrent pregnancy losses (RPL).

Material and methods: In this non-randomized clinical trial, women aged 2245 years with CE diagnosed by positive CD 138 between February 2017 and December 2019 were included. Were investigated 65 women - 30 patients with RPL and 35 women with PI and unsuccessful attempts at IVF. PRP therapy was performed paracervical $(6 \mathrm{ml})$ and intrauterus $(1,5 \mathrm{ml})$ once a week for $4-8$ weeks. Control of the treatment of $\mathrm{CE}$ was performed by endometrial biopsy pipelines 15-20 days after the last PRP.

Results: After carrying out 4 procedures of combined paracervical and intrauterine PRP, CE was cured in $70-77 \%$ of women $(p<0.05)$; after 8 procedures $-97 \%(p<0.01)$.

Conclusions: Combined intrauterine and paracervical PRP therapy is an effective treatment for CE in women with PI and RPL.

Keywords: chronical endometritis, Platelet-rich Plasma, infertility, recurrent pregnancy loss.
Published Online: November 23, 2020

ISSN: 2593-8339

DOI: 10.24018 /ejmed.2020.2.6.560

V. O Sklyarova *

Danylo Halytskyj Lviv National Medical

University, Lviv City Center for Family

Planning and Human Reproduction,

Ukraine.

(e-mail: valisklyarova ${ }^{\circledR}$ hotmail.com)

K. L. Shatylovich

Danylo Halytskyj Lviv National Medical

University, Lviv City Center for Family

Planning and Human Reproduction,

Ukraine.

(e-mail: shatik2@ukr.net)

A. L. Filipyuk

Danylo Halytskyj Lviv National Medical University, Ukraine.

(e-mail: filipyuk_a@ ${ }^{@ k r . n e t)}$

P. O. Sklyarov

Danylo Halytskyj Lviv National Medical

University, Lviv Emergency Hospital,

Ukraine.

(e-mail: sklyarovp777@gmail.com)

R. A. Chajkivskyj

Danylo Halytskyj Lviv National Medical

University, Ukraine.

(e-mail: rostyk @gmail.com)

*Corresponding Author

\section{INTRODUCTION}

The use of platelet-enriched plasma (PRP) in spa conditions in recent years is gaining more and more popularity, not only in cosmetology, but also in women with gynecological problems.

The influence of chronic endometritis (CE) as a factor of infertility and habitual miscarriage is actively discussed in the domestic and world literature [12], [18]. The consequences of this pathology are the inability of women of reproductive age to implement reproductive plans, even after financially costly attempts at IVF, ICSI and donation programs [2], [24], [26]. The peculiarity of aggression of $\mathrm{HE}$ is secondary consequential changes in the endometrium (with positive detection in immunohistochemical study of CD 138) even after the treated primary infectious factors - Ureaplasma urealyticum and parvum, Mycoplasma hominis and genitalium, chronic nonspecific infections [7], [17], [19], [23].

The "gold standard" for the diagnosis of $\mathrm{CE}$ is an immunohistochemical study of the endometrium [1], [5]. Given the literature on the detection of CE in infertility (60-72$90 \%$ ) and pregnancy losses (64-76-86\%), the diagnosis and treatment of this pathology are relevant [4], [6], [16]. Protocol therapeutic tactics are based on complex antibacterial and antiinflammatory therapy, but do not always give $100 \%$ effectiveness and require alternative treatment options [2], [3], [10], [14].

The use of PRP for the treatment of chronic endometritis, due to its antimicrobial and anti-inflammatory properties, has been poorly described in the literature in recent years. Platelets 
contain cytokines, hormones and chemoattractants of stem cells, macrophages and neutrophils, numerous growth factors - vascular endothelial growth factor, platelet growth factor, transforming growth factor beta, growth factor connective tissue growth factor, major fibroblast growth factor, insulinlike growth factor 1 , epidermal growth factor and 2, and hepatocyte growth factor. This in combination provides PRP with mitogenic, chemotactic, neovascular and antiinflammatory effects and the ability to induce cell proliferation [15], [20], [25].

The purpose of this study is to analyze the effectiveness of chronic endometritis treatment in women with infertility and reproductive losses using Platelet-rich Plasma.

\section{MATERIAls AND MethodS}

Survey Women were surveyed at the Lviv City Center for Family Planning at the Danil Halytsky National Medical University.

To achieve this goal, 65 women with confirmed chronic endometritis (positive CD 138) were enrolled, including 30 patients (Group I), with reccurent pregnancy losses (RPL) (N96); Group II - 35 women with primary infertility (PI) for 120 years ( Z31,6, N97, excluded N 97.4) and unsuccessful attempts at IVF.

Prior to the treatment of chronic endometritis, all patients had been examined and treated for genital mycoplasmosis, ureaplasmosis, chlamydia candidiasis, trichomoniasis, herpes I and II types, CMV. He was diagnosed with 7-9 days of menstrual cycle hysteroscopy with material removal (scraping or endometrial biopsy from altered areas) for immunohistochemical and pathomorphological examination. Pathomorphological and immunohistochemical examinations for CD 138 were performed in the CSD laboratory (Kyiv). Data processing was performed using the software package "Statistica", 8.0. In the statistical processing of the results, the percentage of changes, the confidence interval at $p<0.05$, the Pearson xi criterion $\left(\chi^{2}\right)$ and Yates's correction for continuity, the significance of the changes $(p)$ of $\chi^{2}$ criterion were determined.

Control of the treatment of $\mathrm{CE}$ was performed by endometrial biopsy pipelines 15-20 days after the last PRP procedure for 5-7 days of the cycle using ProfiCombi aspiration curette (Simurg, Belarus).

All patients, after signing a voluntary informed consent to treatment, started treatment on day 5-9 of the menstrual cycle. PRP therapy was performed once a week for 4 weeks using the PRP MM MM kit (Zaporozhye, Ukraine, 93/42 / EEC (certificate No. R3M 156289 B1) following the instructions provided by the manufacturer. Obtained autoplasma of approximately 8-9 ml. prepared PRP for infusions of $18 \mathrm{ml}$ of blood (2 tubes) was injected paracervical $(6-7 \mathrm{ml})$ with the help of an insulin syringe on the dial at the rate of $0.7-1 \mathrm{ml}$ per injection and intrauterine $(2-2.5 \mathrm{ml})$ using the appropriate catheter (Simurg, Belarus).

\section{Results OF THE ReSEARCH}

Given that all patients with detectable CE had received etiopathogenetic antibacterial and anti-inflammatory therapy by the stage of treatment, therapeutic tactics included only PRP therapy. The effectiveness of treatment for the definition of diabetes 138 in women of both groups after 4 and 8 PRP procedures are presented in Table. 1 .

TABLE 1: DETECTION OF CHRONIC ENDOMETRITIS IN WOMEN WITH INFERTILITY AND HABITUAL MISCARRIAGE OF THE PRP THERAPY

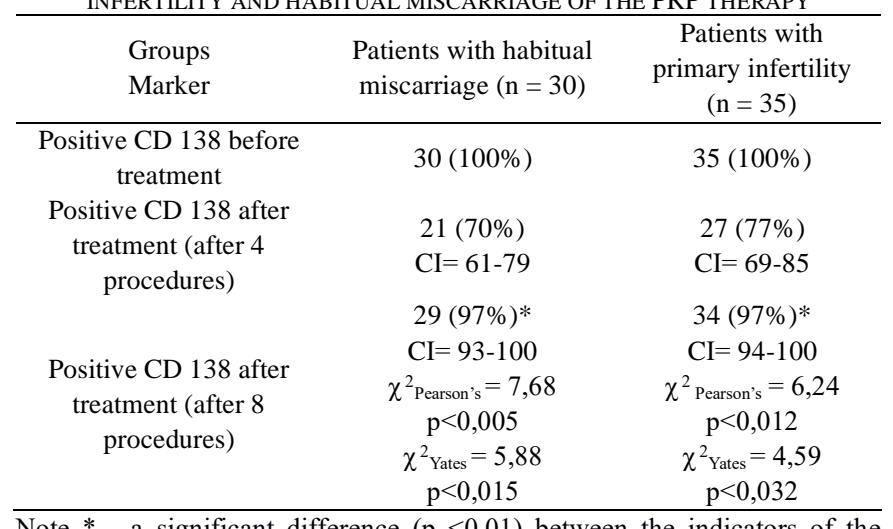

Note * - a significant difference $(\mathrm{p}<0,01)$ between the indicators of the examined women before and after treatment.

According to the recommendations of the literature, treatment tactics for PRP therapy to obtain effective treatment should include 6-8 procedures [9]. Patients who failed to eliminate $\mathrm{CE}$ after the first course were advised to repeat 4 more PRP therapy procedures, followed by monitoring for CD 138 after 15-20 days.

After carrying out 8 procedures of combined paracervical and intrauterine PRP, chronic endometritis was cured in $97 \%$ of women with habitual miscarriage and infertility. Statistical processing of the results indicates the reliability of the effect obtained after 8 PRP therapy procedures $(\mathrm{p}<0.01)$.

The results of this work represent a non-standard and nonprotocol approach to patients with CE who have not responded to the etiopathogenetic treatment after previous antibiotic regimens. Although 100\% efficacy has not been obtained after autologous PRP treatment, the results of our work suggest the use of a combined autologous intrauterine and paracervical PRP method for the treatment of women with CE and infertility and habitual pregnancy miscarriage.

\section{Discussion}

Over the last 10 years, an in vivo study of autologous PRP for endometrial women with reproductive health pathology in $\mathrm{CE}$ has been gaining momentum [8], [11], [13], [15]. The results of all studies have shown that autologous PRP is effective for repairing damaged endometrium, improving pregnancy outcomes in natural cycles and IVF, pregnancy delivery after previous loss [9], [21], [22].

The effectiveness and ease of use of PRP therapy in various areas of gynecology makes it widely applicable, but the procedure for preparing PRP is not standardized. Most authors 
use intrauterine injection of PRP, but in our opinion combined with paracervical injection into the parameter improves the effectiveness of treatment of CE. In our opinion, the main mechanisms by which PRP paracervical administration enhances intrauterine procedures are the effect on pro and antiinflammatory systems in parameters, increasing the release of various growth factors (insulin-like growth factor-I, fibroblast growth factor, vascular endothelial growth factor) in the lymphatic system increased relocation of leukocytes around the affected tissue. Given that the use of regenerative properties of PRP infusions (in the experience of face cosmetology) contributes to the rejuvenation of the lower parts of the reproductive system, and the proliferation of stem cells.

\section{CONCLUSIONS}

1. Combined intrauterine and paracervical PRP therapy is an effective treatment for chronic endometritis in women with infertility and reproductive loss.

2. After 4 PRP procedures, chronic endometritis was treated histochemically in $70 \%$ of women with habitual miscarriage and in $77 \%$ of women with infertility. Statistical processing of the results indicates the reliability of the effect obtained after 8 PRP therapy procedures of combined paracervical and intrauterine PRP ( $\mathrm{p}<0.01)$.

Conflict of interest the author(s) declared no potential conflicts of interest with respect to the research, authorship, and/or publication of this article.

\section{ACKNOWLEDGEMENT}

The authors thank Dr Kozytska Viktoria for nice help on methodology.

\section{REFERENCES}

[1] Alonso L, Carugno J. Chronic Endometritis: Three-dimensional Ultrasound and Hysteroscopy Correlation. J Minim Invasive Gynecol. 2019;3.

[2] Bashiri A., Halper K.I., Orvieto R. Recurrent Implantation Failureupdate overview on etiology, diagnosis, treatment and future directions. Reprod Biol Endocrinol. 2018;16(1):121.

[3] Bos-Mikich A., Ferreira M.O., Oliveira R., Frantz N. Platelet-rich plasma or blood-derived products to improve endometrial receptivity? Journal of Assisted Reproduction and Genetics 2019; 36:613-620.

[4] Cakiroglu Y, Tiras B. Determining diagnostic criteria and cause of recurrent implantation failure. Curr Opin Obstet Gynecol. 2020;3.

[5] Chen Y.Q., Fang R.L., Luo Y.N., Luo C.Q. Analysis of the diagnostic value of CD138 for chronic endometritis, the risk factors for the pathogenesis of chronic endometritis and the effect of chronic endometritis on pregnancy: a cohort study. BMC Womens Health. 2016;16(1):60.

[6] Cicinelli E., Matteo M., Trojano G et al. Chronic endometritis in patients with unexplained infertility: Prevalence and effects of antibiotic treatment on spontaneous conception. Am J Reprod Immunol. 2018;79(1).

[7] Cicinelli E., Trojano G., Mastromauro M. et al. Higher prevalence of chronic endometritis in women with endometriosis: a possible etiopathogenetic link. Fertil Steril. 2017;108(2):289-295.

[8] Coksuer H., Akdemir Y., Barut M.U. Improved in vitro fertilization success and pregnancy outcome with autologous platelet-rich plasma treatment in unexplained infertility patients that had repeated implantation failure history. Gynecological Endocrinology 2019;35:9.
[9] Eftekhara M., Neghaba N., Naghshinehb E., Khania P. Can autologous platelet rich plasma expand endometrial thickness and improve pregnancy rate during frozen-thawed embryo transfer cycle? A randomized clinical trial. Taiwanese Journal of Obstetrics and Gynecology 2018; 57(6):810-813.

[10] Franasiak J.M. Chronic endometritis is associated with an altered microbiome, but what about treatment and clinical outcomes? Fertil Steril. 2019 Oct;112(4):649-650.

[11] Javaheri A., Kianfar K., Pourmasumi S., Eftekhara M. Platelet-rich plasma in the management of Asherman's syndrome: An RCTInt J Reprod Biomed (Yazd). 2020 Feb; 18(2): 113-120.

[12] Kimura F, Takebayashi A, Ishida M Review: Chronic endometritis and its effect on reproduction. J Obstet Gynaecol Res. 2019;45(5):951-960.

[13] Kitaya K., Matsubayashi H., Takaya Y., et al. Live birth rate following oral antibiotic treatment for chronic endometritis in infertile women with repeated implantation failure. Am J Reprod Immunol. 2017; 78: e12719.

[14] Kosei N, Zakharenko N, Herman D. Endometrial polyps in women of reproductive age: clinical and pathogenetic variations. Georgian Med News. 2017;(273):16-22.

[15] Madhavan A., Naidu P., Rani K.K., Kaur J., Mahajan N. Intrauterine autologous platelet-rich plasma therapy to improve implantation rates in patients undergoing frozen embryo transfer: A pilot study. Onco Fertil J 2018; 1:81-5.

[16] McQueen D.B., Bernardi L.A., Stephenson M.D. Chronic endometritis in women with recurrent early pregnancy loss and/or fetal demise. Fertil. Steril 2014;4(101):1026-1030.

[17] Mlodzik N, Lukaszuk K, Sieg W, Jakiel G, Smolarczyk R.Endometrial microbiota - do they mean more than we have expected? Ginekol Pol. 2020;91(1):45-48.

[18] Pyrohova, V. I., \& Shurpiak, S. O. Terapiia khronichnoho endometrytu u zhinok z porushenniamy reproduktyvnoho zdorov'ia $\mathrm{z}$ pozytsii podolannia oksydatyvnoho stresu [Therapy of chronic endometritis in women with impaired reproductive health from the standpoint of overcoming oxidative stress]. Zdorov'e zhenshchiny 2015; 6:60-64.

[19] Puente E., Alonso L., Laganà A.S. et al. Chronic Endometritis: Old Problem, Novel Insights and Future Challenges. Int J Fertil Steril. 2020;13(4):250-256.

[20] Samy A., Abbas A.M., Elmoursi A., Elsayed M., Hussein R.S. Effect of autologous platelet-rich plasma transfusion in the treatment of infertile women with thin endometrium and its implications in IVF cycles: a literature review. Middle East Fertility Society Journal 2020;25(5):368

[21] Sfakianoudis K., Simopoulou M., Nitsos M. et al. Successful Implantation and Live Birth Following Autologous Platelet-rich Plasma Treatment for a Patient with Recurrent Implantation Failure and Chronic Endometritis In Vivo. 2019; 33(2): 515-521.

[22] Sklyarova V. O. Treatment of chronic endometritis in infertility in patients with a transmitted parasitic lesion. Internet presentation of posters of the $4^{\text {Th }}$ SEUD Congress. Florence, Italy. 26-28 April 2018. 217. URL: http://seud.org/217-sklyarova/.

[23] Sklyarova V.A. Treatment of mixed urogenital infection in women of reproductive age with parasitic lesions. Clinical pharmacy, pharmacotherapy and medical standardization. 2014;3-4(24-25):112115.

[24] Song D., Li T.C., Zhang Y. et al. Correlation between hysteroscopy findings and chronic endometritis. Fertil Steril. 2019;111(4):772-779.

[25] Qureshi A.H., Chaoji V., Maiguel D. et al. Proteomic and PhosphoProteomic Profile of Human Platelets in Basal, Resting State: Insights into Integrin Signaling. PLoS ONE. 2009; 4: e7627.

[26] Yang R., Du X., Wang Y. et al. The hysteroscopy and histological diagnosis and treatment value of chronic endometritis in recurrent implantation failure patients. Arch Gynecol Obstet. 2014;289(6):13631369. 